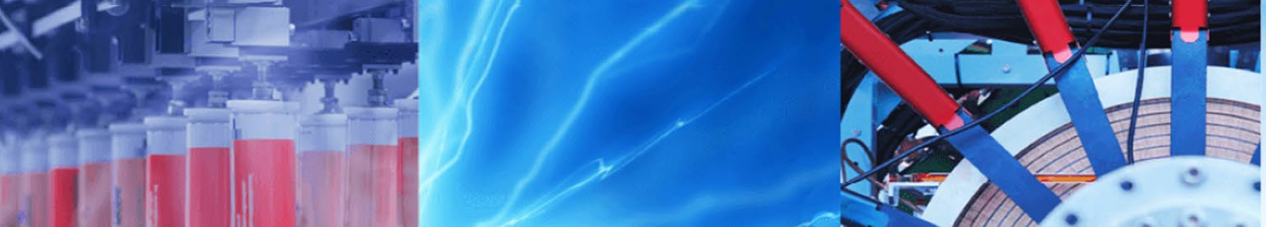

Research Article

\title{
Structural, surface morphological, optical and thermoelectric properties of sol-gel spin coated Zn doped CdS thin films
}

\author{
Munaga Venkata Veera Prasad ${ }^{1}$ (1) $\cdot$ Krishnan Thyagarajan $^{2} \cdot$ Borra Rajesh Kumar $^{3}$
}

Received: 3 December 2019 / Accepted: 27 February 2020 / Published online: 4 March 2020

(c) Springer Nature Switzerland AG 2020

\begin{abstract}
The present work is focussed on Zinc $(2,4,6,8$ and 10 wt\%) doped CdS thin films synthesized by sol-gel spin coating method and deposited on glass substrates. X-ray diffraction patterns of $Z n$ doped $C d S$ thin films exhibit cubic structure. The microstructural properties such as crystallite size, lattice constant, microstrain, dislocation density and stacking fault probability in the films were reported. The surface morphology and topography of the films was studied by using field emission scanning electron microscopy and atomic force microscopy. The incorporation of $\mathrm{Zn}$ in $\mathrm{CdS}$ and elemental composition of the films has been confirmed with X-ray photoelectron spectroscopy (XPS) and energy dispersive spectroscopy (EDS). Raman spectrum of Zn doped CdS thin films exhibits $1 \mathrm{LO}$ and $2 \mathrm{LO}$ phonon modes. The optical band gap of CdS thin films increased from 2.63 to $2.73 \mathrm{eV}$ with the increase of $\mathrm{Zn}$ dopant from 2 to $10 \%$. Thermoelectric power measurements show negative Seebeck coefficient indicating $n$-type semiconducting behaviour. The carrier concentration of $\mathrm{Zn}$ doped $\mathrm{CdS}$ thin films at room temperature are found to be in the range of $10^{19}-10^{20} \mathrm{~cm}^{-3}$ suggesting that the prepared films are degenerate semiconductors. The increase in thermal conductivity of $\mathrm{Zn}$ doped $\mathrm{CdS}$ thin film is due to the increase in carrier concentration of the films. The lattice thermal conductivity of $Z n$ doped CdS thin films had an inverse temperature dependent and at high temperatures shows the dominance of phonon scattering.
\end{abstract}

Keywords II-VI semiconductor $\cdot$ Thin films · Structural properties $\cdot$ Thermoelectric properties

\section{Introduction}

Nowadays, ternary or quaternary chalcogenide semiconducting materials are of scientific interest because the physical properties can be tuned to meet the specific requirements in the electronic device fabrication [1]. Ternary chalcogenide semiconductors like $\mathrm{Cd}-\mathrm{Zn}-\mathrm{X}$ $(X=S, S e)$ become more interest because of possibility in tuning the electronic properties. These chalcogenide semiconductors exhibit a wide direct band gap value in the range of 2.4-3.7 eV. Based on relative composition of $\mathrm{Cd}: Z n$ ratio, it is utilized in blue and ultraviolet laser diodes, window layers for solar cells, antireflection coatings for IR (infrared) devices, electroluminescence and low-voltage cathode luminescence [2, 3]. Experimental investigations on doping of $\mathrm{Zn}$ in $\mathrm{CdS}$ will enhance the optoelectronic properties and its applications in energy, electronics, and optoelectronic devices. Zinc is a worthy element with an ionic radius of $0.074 \mathrm{~nm}$, smaller than the ionic radius of Cadmium $\left(\mathrm{Cd}^{2+}=0.097 \mathrm{~nm}\right)$, so that the Zinc $\left(\mathrm{Zn}^{2+}\right)$ can incorporate in $\mathrm{CdS}$ lattice or substitute $\mathrm{Cd}^{2+}$ position in the crystal lattice [4]. The incorporation of $\mathrm{Zn}$ in $\mathrm{CdS}$ will increase the resistivity of the material and diffusion length [5]. The high band gap makes the film transparent in all the wavelengths of solar spectrum and decreases the window absorption losses [6]. Ternary semiconducting compounds

\footnotetext{
$\triangle$ Munaga Venkata Veera Prasad, mvvp.physics@gmail.com | ${ }^{1}$ Department of Physics, JNTU Anantapur, Anantapur, A.P. 515002, India. ${ }^{2}$ Department of Physics, JNTUA College of Engineering, Pulivendula, A.P. 516 390, India. ${ }^{3}$ Department of Electronics and Physics, GITAM (Deemed To Be University), Visakhapatnam, A.P. 530 045, India.
} 
are of great interest for studying the thermoelectric properties because of their good thermoelectric performance, generally depends on the figure of merit of a material, defined as $Z T=\left(S^{2} / \rho \cdot k\right) T$ where $S, \rho, T$ and $k$ represent the Seebeck coefficient, electrical resistivity, absolute temperature and total thermal conductivity, which is composed of electronic $\left(k_{e}\right)$ and lattice contribution $\left(k_{\mathrm{L}}\right)$ respectively. Thermoelectric measurements of semiconductors provide information on the effective mass of charge carriers, free carrier concentration and the scattering mechanism.

Different techniques such as chemical bath deposition [7], vacuum evaporation [8], spray pyrolysis [9], spin coating [10], sputtering [11], chemical vapour deposition [12], molecular beam epitaxy [13], sol-gel [14], successive ionic layer and reaction (SILAR) [15] have been performed for the synthesis of $Z n$ doped $C d S$ nanostructured thin films. Among these methods, the sol-gel spin coating technique had an advantage like low cost with simple working principle, easy compositional modifications and its ability to quickly produce very uniform thin films ranging from few nanometres to microns in thickness low annealing temperature and large growth area of the film [16]. The main objective of the present work is to prepare $\mathrm{Zn}$ doped $\mathrm{CdS}$ thin films by a low-cost sol-gel spin coating technique and it can be utilized as a n-type window layer in thin film solar cells. Even though many literatures [17-22] focussed on structural, electrical and optical properties of $\mathrm{Zn}$ doped CdS samples, studies on the thermoelectric properties are still scanty. As reviewed from the previous literature survey, there are less reports on the thermoelectric properties of $\mathrm{Zn}$ doped $\mathrm{CdS}$ thin films.

\section{Experimental details}

\subsection{Synthesis}

Cadmium nitrate tetrahydrate $\left(\mathrm{Cd}\left(\mathrm{NO}_{3}\right)_{2} \cdot 4 \mathrm{H}_{2} \mathrm{O}\right)$, Zinc nitrate hexahydrate $\left(\mathrm{Zn}\left(\mathrm{NO}_{3}\right)_{2} \cdot 6 \mathrm{H}_{2} \mathrm{O}\right)$, thiourea $\left(\mathrm{CS}\left(\mathrm{NH}_{2}\right)_{2}\right)$ and ethanol were used as precursors and solvent. All the chemicals purchased from Merck chemical Co., with high purity (99.99\%) AR grade and used without further purification. Solution 1 is considered as by adding $0.6 \mathrm{ml}$ of Polyethylene Glycol (PEG 200, Merck, India), $8.9 \mathrm{ml}$ of ethanol and $0.5 \mathrm{ml}$ of acetic acid in a beaker by stirring $1 \frac{1}{2} \mathrm{~h}$. The precursors were dissolved in ethanol in another beaker by stirring $90 \mathrm{~min}$ at $60^{\circ} \mathrm{C}$ to obtain solution 2 . The zinc doping concentrations in solution 2 are varied from 0.01 to $0.05 \mathrm{M}$ to obtain $2,4,6,8$ and $10 \%$. Now the solution 2 is mixed with solution 1 drop wise for $5 \mathrm{~h}$ with continuous stirring until the value of $\mathrm{pH}$ reaches 10 . Then the final solution is used for the preparation of $\mathrm{Zn}$ doped $\mathrm{CdS}$ thin films on glass substrates using a spin coater (Model No. spin NXG-P1, Apex instruments, India) with a speed of $1500 \mathrm{rpm}$ for $45 \mathrm{~s}$. Before the deposition, the substrates were cleaned with double-distilled water, acetone and in ultrasonic heater. After the deposition, the films were dried on hot plate at $100{ }^{\circ} \mathrm{C}$ for $10 \mathrm{~min}$ and then annealed at $200^{\circ} \mathrm{C}$ in muffle furnace for $1 \mathrm{~h}$.

\subsection{Characterization}

The crystal structure and crystallographic orientation of the films were investigated by X-ray diffractometer (Model: Rigaku Ultima III) using Cu-Ka radiation with a wavelength $\lambda=0.154 \mathrm{~nm}$. The diffraction patterns were recorded at an operative voltage of $40 \mathrm{kV}$ and current $30 \mathrm{~mA}$ at an angle of incidence $1^{\circ}$ with a scan range $(2 \theta)$ from $10^{\circ}$ to $80^{\circ}$. The surface morphology of the films has been determined by field emission scanning electron microscope (FESEM) (Model: ULTRA-55, KARL ZIESS) and atomic force microscopy (AFM) (Model: Bruker). The quantitative elemental analysis of $\mathrm{Zn}$ doped $\mathrm{CdS}$ thin films were analysed by energy dispersive X-ray spectroscopy (EDS, Oxford Instruments) assembled with FESEM unit. The binding energy and surface composition of the elements in the film is recorded by $\mathrm{X}$-ray photoelectron spectroscopy (Model: AXIS ULTRA-165). The Raman spectra of the films were recorded by LabRAM HR. The thickness of the film measured by Talysurf profilometer is in the range of 250-300 nm. The optical absorption spectra of the films were measured using UV-VIS-NIR spectrophotometer in the wavelength range of $300-800 \mathrm{~nm}$. The thermoelectric properties of the films were determined by the integral method and measured the electromotive force (emf) developed across the film. The emf developed across the two copper leads of Cu-constantan thermocouples was maintained at the cold and hot ends are noted. The thermal emf is measured with a Keithley 2400 source meter in the temperature range of $313-453 \mathrm{~K}$.

\section{Results and discussion}

\subsection{X-ray diffraction}

Figure 1 shows X-ray diffraction (XRD) patterns of different concentrations of $Z n$ doped $C d S$ thin films. The presence of peaks in the XRD spectra confirms the crystallinity and exhibit cubic zinc blende structure. The films exhibit three significant diffraction peaks related to (1 1 1), (2 20$)$, ( ( $\left.\begin{array}{lll}3 & 1 & 1\end{array}\right)$ with a preferred orientation along (1 11 1) at $2 \theta$ values given in Table 1 . The observed peaks are well matched with the JCPDF No. 40-0836 and found to be good in agreement with the reported data on CdZnS [23]. The phase and purity of the prepared $\mathrm{Zn}$ doped $\mathrm{CdS}$ 

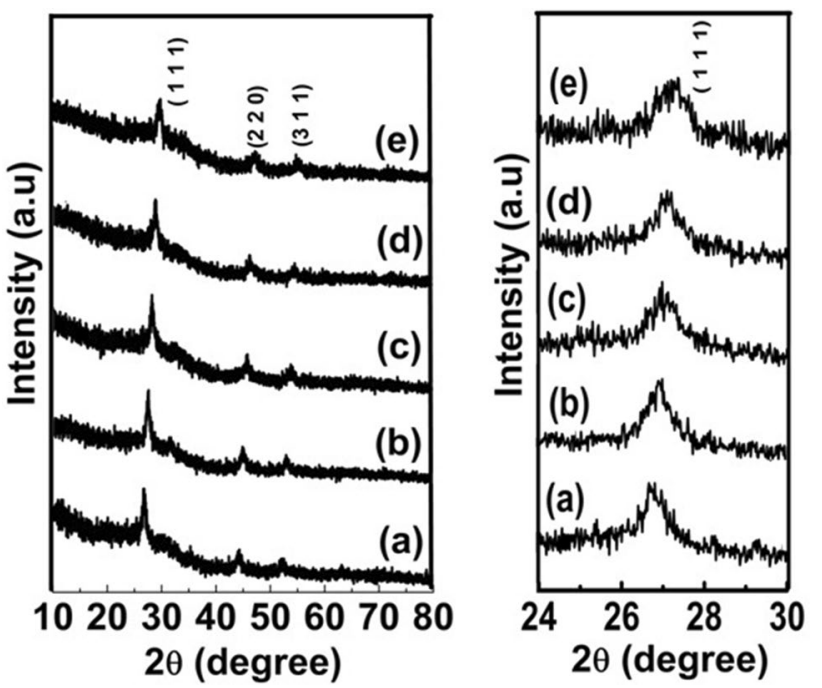

Fig. 1 XRD patterns for (a) 2\%, (b) 4\%, (c) 6\%, (d) $8 \%$ and (e) $10 \% \mathrm{Zn}$ doped CdS thin films and enlarged X-ray spectra along (1 111 ) plane from $24^{\circ}$ to $30^{\circ}$

thin films were confirmed by $\mathrm{X}$-ray diffraction peaks i.e., no extra peaks for oxides/sulphides of $\mathrm{CdS}$ or other planes are found. A shift of ( 1111 ) diffraction peak towards the higher angle is noticed, indicating the contraction in the CdS thin films with Zn doping (enlarged X-ray spectra along ( $\left.\begin{array}{lll}1 & 1 & 1\end{array}\right)$ plane from $24^{\circ}$ to $30^{\circ}$ is shown in side view of Fig. 1). No change in structural phase is noticed with the effect of $\mathrm{Zn}$ in CdS thin films but introduces a decrease in the lattice constant. The lattice parameter 'a' of the films is calculated using the relation $a=d \cdot\left(h^{2}+k^{2}+l^{2}\right)^{1 / 2}$. The values of lattice parameter slightly decreased from 0.5786 to $0.5721 \mathrm{~nm}$ with the increase of $\mathrm{Zn}$ concentration in CdS. The lattice contraction is observed due to the strain induced in the films and due to ionic radii difference between the dopant ion $\mathrm{Zn}^{2+}(=0.074 \mathrm{~nm})$ and host ions $\mathrm{Cd}^{2+}(=0.097 \mathrm{~nm})$, $\mathrm{S}^{2-}(=0.184 \mathrm{~nm})$. The FWHM of the diffraction peak $\left(\begin{array}{lll}1 & 1 & 1\end{array}\right)$ increases from $0.44^{\circ}$ to $1.15^{\circ}$ with the increase of $\mathrm{Zn}$ concentration. The crystallite size (D) estimated from Scherer formula is decreased from 19.4 to $7.4 \mathrm{~nm}$ with the increase of $\mathrm{Zn}$ concentration in CdS. The decrease in the crystallite size may be due to incorporation of $\mathrm{Zn}^{2+}$ ions into the $\mathrm{Cd}^{2+}$ sites. The number of crystallites per unit area $(\mathrm{N})$ of $\mathrm{Zn}$ doped CdS thin films have been calculated using the film thickness ( $\mathrm{t}$ ) and crystallite size (D) by the relation, $\mathrm{N}=\mathrm{t} /$ $D^{3}$. The number of crystallites per unit area $(N)$ is in the range of $(0.27-4.89) \times 10^{17} \mathrm{~m}^{-2}$, increased with the increase of $\mathrm{Zn}$ dopant in $\mathrm{CdS}$ due to decrease in crystallite size of the films. Similar results have been reported by Ligang Ma et al. [24] for $\mathrm{Zn}$ doped CdS thin films prepared by chemical bath deposition method. The microstrain $(\varepsilon)$, dislocation density $(\delta)$ and stacking fault probability $\left(a_{S}\right)$ of the films were calculated from the equations as reported in earlier literature $[25,26]$. The increase in these microstructural parameters is responsible for the peak broadening with reduction in lattice imperfections and the presence of defects and vacancies. The microstructural parameters of $\mathrm{Zn}$ doped $\mathrm{CdS}$ thin films are reported in Table 1.

\subsection{Surface morphology}

FESEM is considered to be one of the promising techniques to know the surface morphology of the films. It is especially used for the topographical studies of the films and to know the information regarding the shape, size and growth mechanism. Figure 2a-e shows the FESEM images of different concentrations of $\mathrm{Zn}$ doped $\mathrm{CdS}$ thin films. Porosity and agglomeration of small crystallites are present in certain regions of $Z n$ doped $C d S$ thin films shown in Fig. 2a-c. With the increase of $\mathrm{Zn}$ dopant from 8 to $10 \%$ in CdS thin films the grains are relatively smaller in size and dense distribution is noticed over the surface with good connectivity between the grains (shown in Fig. $2 \mathrm{~d}$, e). FESEM micrographs reveal the decrement of grain size with the increase of $\mathrm{Zn}$ content in CdS thin films.

\subsection{AFM analysis}

Two dimensional (2D) and three dimensional (3D) atomic force microscopy (AFM) images of Zn doped CdS thin films

Table 1 Structural parameters of $\mathrm{Zn}$ doped CdS thin films

\begin{tabular}{|c|c|c|c|c|c|c|c|c|c|}
\hline $\begin{array}{l}\text { Doping con- } \\
\text { centration of } \\
\mathrm{Zn}(\mathrm{at} \%)\end{array}$ & $2 \theta\left(^{\circ}\right)$ & $\mathrm{FWHM}\left({ }^{\circ}\right)$ & $\begin{array}{l}\text { d-spacing } \\
(\mathrm{nm})\end{array}$ & $\begin{array}{l}\text { Lattice } \\
\text { constant, a } \\
(\mathrm{nm})\end{array}$ & $\begin{array}{l}\text { Crystal- } \\
\text { lite size, D } \\
(\mathrm{nm})\end{array}$ & $\begin{array}{l}\text { Number } \\
\text { of crystal- } \\
\text { lites per } \\
\text { unit area, N } \\
\left(\times 10^{17} \mathrm{~m}^{-2}\right)\end{array}$ & $\begin{array}{l}\text { Micro strain, } \varepsilon \\
\left(\times 10^{-3} \operatorname{lin}^{-2} \mathrm{~m}^{-2}\right)\end{array}$ & $\begin{array}{l}\text { Dislocation } \\
\text { density, } \delta \\
\left(\times 10^{17} \text { lin } \mathrm{m}^{-2}\right)\end{array}$ & $\begin{array}{l}\text { Stacking fault } \\
\text { probability, } a_{S}\end{array}$ \\
\hline 2 & 26.66 & 0.44 & 0.3341 & 0.5786 & 19.4 & 0.27 & 1.87 & 0.51 & 6.33 \\
\hline 4 & 26.78 & 0.53 & 0.3326 & 0.5761 & 16.1 & 0.48 & 2.25 & 0.62 & 4.08 \\
\hline 6 & 26.82 & 0.70 & 0.3320 & 0.5751 & 12.2 & 1.10 & 2.97 & 8.21 & 3.33 \\
\hline 8 & 26.90 & 1.06 & 0.3310 & 0.5734 & 8 & 3.83 & 4.50 & 1.24 & 1.85 \\
\hline 10 & 26.96 & 1.15 & 0.3303 & 0.5721 & 7.4 & 4.89 & 4.88 & 1.35 & 0.74 \\
\hline
\end{tabular}



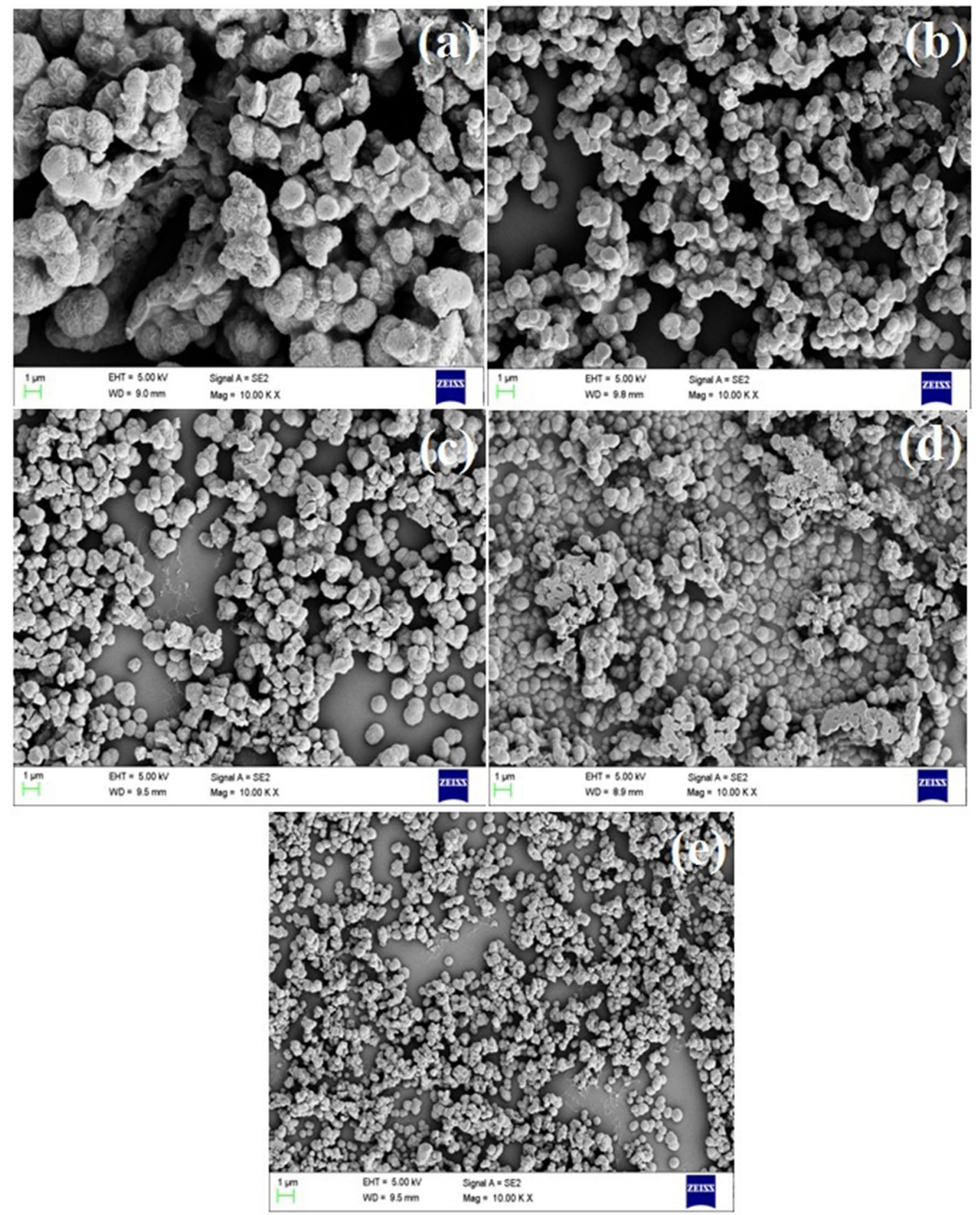

Fig. 2 FESEM images of a $2 \%$, b 4\%, c 6\%, d $8 \%$ and e $10 \%$ Zn doped CdS thin films

(scan area of $5 \mu \mathrm{m} \times 5 \mu \mathrm{m}$ ) are shown in Fig. 3a-e. AFM analysis exhibit that the $\mathrm{Zn}$ incorporation in CdS thin films will affect in the rms surface roughness and grain size. The reduction ingrain size with the increase of $Z n$ content in $\mathrm{CdS}$ thin films can be clearly noticed in the AFM analysis. The AFM image of $2 \mathrm{wt} \% \mathrm{Zn}$ incorporated CdS film presents smaller grains agglomerated with no definite grain boundary. The surface morphology of the films with 4 to 10 wt $\% \mathrm{Zn}$ in CdS have a well-defined grains. CdS film doped with $10 \mathrm{wt} \% \mathrm{Zn}$ presents a surface morphology with uniformly distributed smaller grains. A similar type of surface morphology was found in the literature Chalana

\section{SN Applied Sciences}


Fig. 3 AFM 2D and 3D mages of a $2 \%$, b $4 \%$, c $6 \%$, d $8 \%$ and e $10 \% \mathrm{Zn}$ doped $\mathrm{CdS}$ thin films
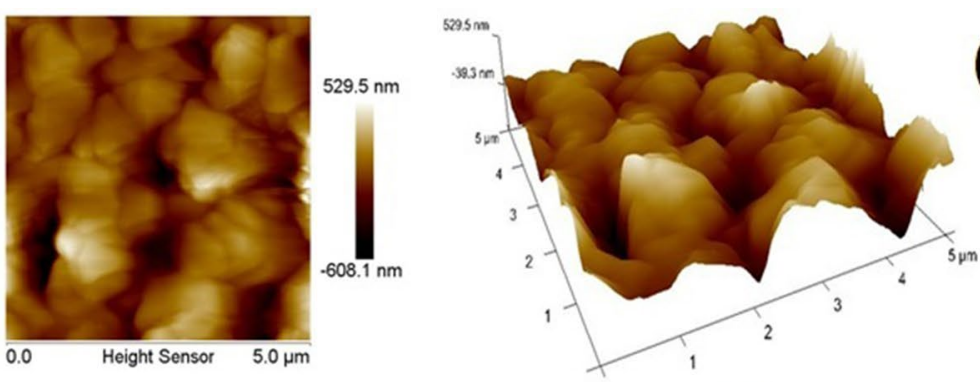

(a)
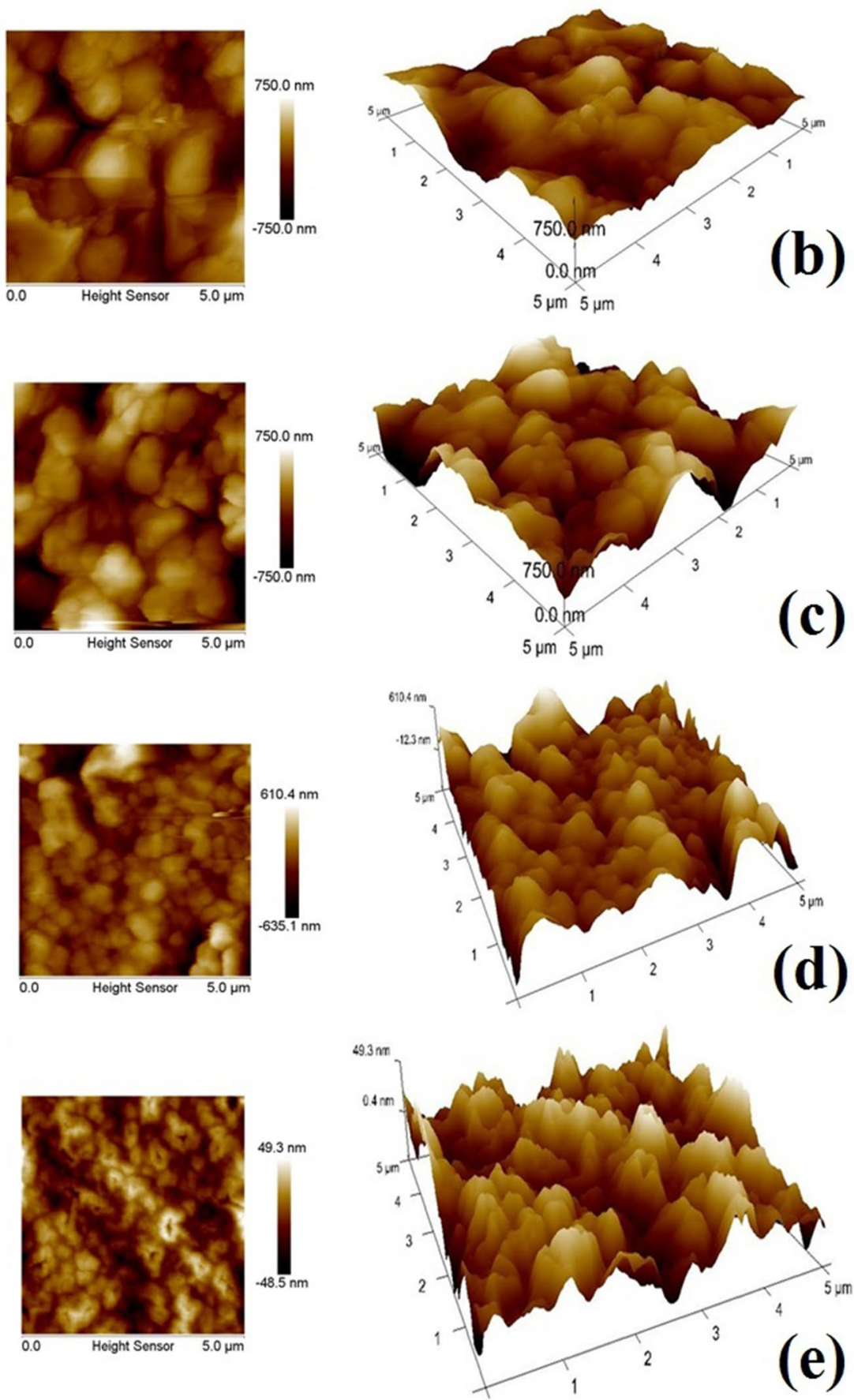
et al. [27]. The reduction of the grain size with the increase of $\mathrm{Zn}$ dopant in $\mathrm{CdS}$ thin films is in good agreement with the XRD results. The rms surface roughness for $2,4,6,8$ and $10 \mathrm{wt} \% \mathrm{Zn}$ in $\mathrm{CdS}$ thin films were found to be 22.1, $18.3,16.2,13.6$ and $11.8 \mathrm{~nm}$ respectively. The decrease of rms surface roughness with the increase of $\mathrm{Zn}$ dopant in CdS makes the films smoother and these features are particularly important for manufacturing optoelectronic devices and solar cells.

\subsection{Compositional analysis with EDS}

An energy dispersive X-ray spectroscopy (EDS) is used to know the elemental composition of the films. Figure $4 a-e$ shows the energy dispersive $X$-ray spectra for $Z n$ doped $\mathrm{CdS}$ thin films. Peaks confirm the presence of $\mathrm{Cd}, \mathrm{Zn}$ and $S$ in the prepared thin films. The atomic percentage compositions of the elements $\mathrm{Cd}, \mathrm{S}$ and $\mathrm{Zn}$ are compiled in Table 2. It is noticed from the Table 2 that weight percentage of $\mathrm{S}$ is constant and Cd percentage is decreased when $\mathrm{Zn}$ doping percentage is varied from 2 to $10 \%$.

\subsection{X-ray photoelectron spectroscopy (XPS) analysis}

X-ray photoelectron spectroscopy (XPS) is used to know the valence states of the material and surface composition. Figure 5 a shows the wide region XPS spectrum of $6 \% \mathrm{Zn}$ doped CdS thin film. The wide energy spectrum
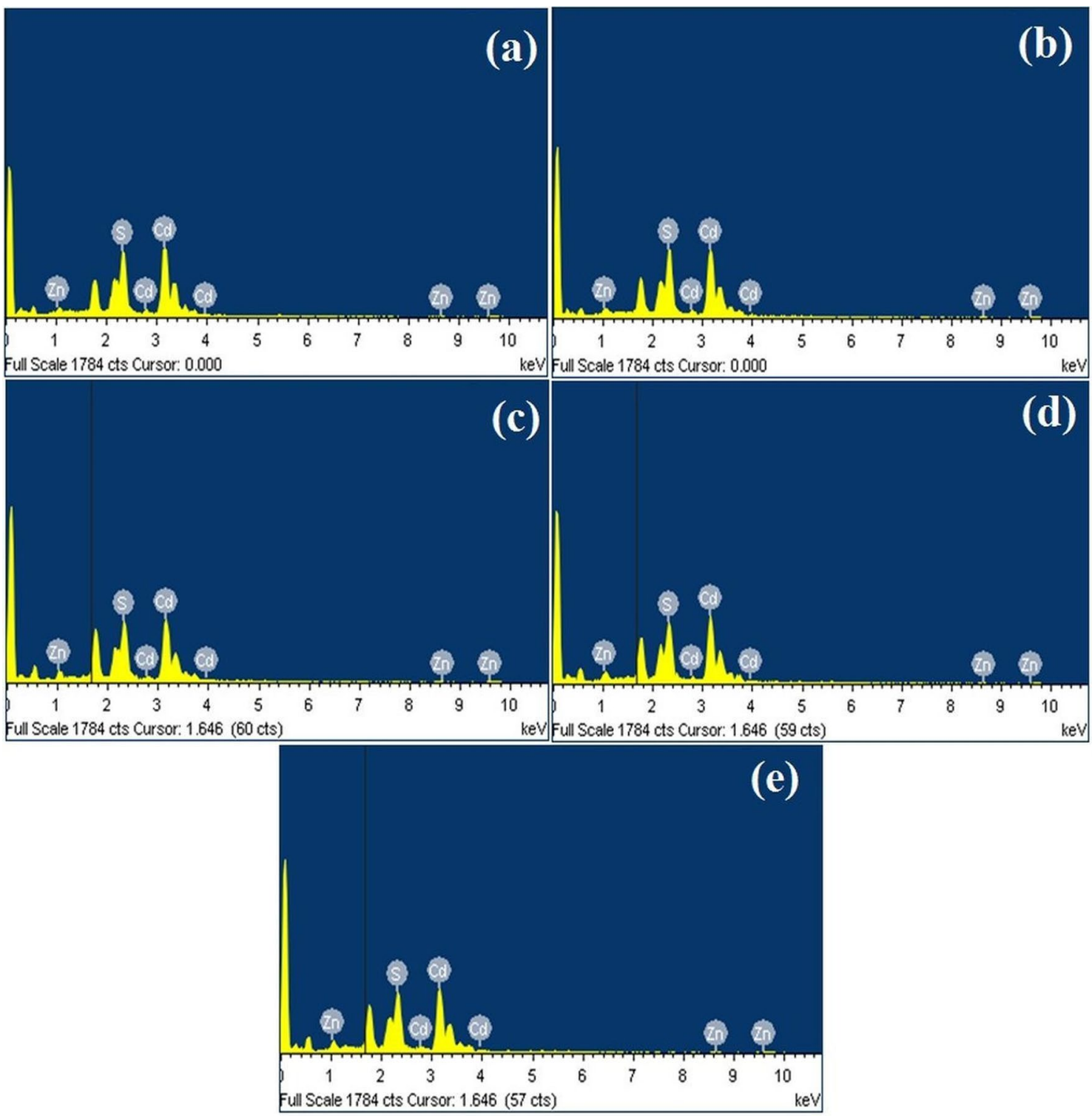

Fig. 4 EDS analysis of a $2 \%$, b $4 \%$, c $6 \%$, d $8 \%$ and e $10 \%$ Zn doped CdS thin films 
Table 2 Elemental composition of $\mathrm{Zn}$ doped CdS thin films

\begin{tabular}{llll}
\hline $\begin{array}{llll}\text { Doping concentration of } \\
\text { Zn (wt\%) }\end{array}$ & \multicolumn{3}{l}{ Element (wt\%) } \\
\cline { 2 - 4 } & $\begin{array}{l}\mathrm{Cd} \\
\mathrm{L}\end{array}$ & $\mathrm{S}$ & $\mathrm{Kn}$ \\
& $\mathrm{K}$ & $\mathrm{K}$ \\
\hline 2 & 54.73 & 43.59 & 1.68 \\
4 & 56.26 & 41.38 & 2.36 \\
6 & 55.02 & 39.36 & 5.62 \\
8 & 56.68 & 38.96 & 7.42 \\
10 & 59.71 & 34.09 & 9.23 \\
\hline
\end{tabular}

shows the presence of cadmium (Cd), zinc ( $\mathrm{Zn})$, and sulphur (S) elements in the film. The peaks of $\mathrm{O}, \mathrm{Na}$, and $\mathrm{Si}$ were mainly caused by the glass substrate and surface contamination. The spectrum observed in Fig. $5 \mathrm{~b}$ is in the range of $150-170 \mathrm{eV}$ was identified as the $2 \mathrm{p}$ spectrum of $\mathrm{S}$ in metal sulphides. The peak at $160.1 \mathrm{eV}$ corresponds to $S 2 p_{3 / 2}$ is attributed to monosulfide $S^{-2}$ and the peak at $162.4 \mathrm{eV}$ corresponds to $\mathrm{S} 2 \mathrm{p}_{1 / 2}$ which is the characteristic of a disulphide $\mathrm{S}^{2-}$ phase. In Fig. $5 \mathrm{c}$, the $\mathrm{Cd} 3 \mathrm{~d}$ core level exists the peaks at 403 and $410 \mathrm{eV}$ corresponding to $C d 3 d_{5 / 2}$ and $C d 3 d_{3 / 2}$ respectively which were characteristic peaks of $\mathrm{Cd}^{2+}$ in CdS. Figure $5 d$ shows the $\mathrm{Zn} 2 \mathrm{p}$ spectrum having two sharp peaks at 1020 and $1043 \mathrm{eV}$ corresponding to $Z n 2 p_{3 / 2}$ and $Z n 2 p_{1 / 2}$ respectively with a doublet separation of $23 \mathrm{eV}$ which can be attributed to the bivalent $Z n$. The peak corresponding to $Z n 2 p_{3 / 2}$ could be attributed to the existence of $Z n^{2+}$. XPS survey shows that the $6 \% \mathrm{Zn}$ doped $\mathrm{CdS}$ thin film contain vacancy sulfur, carbon and oxygen impurities which plays a key influence to improve the photoelectric properties.

\subsection{Raman spectroscopy}

Raman spectroscopy confirms the crystallinity of the films by analysing the vibration phonon bands and spectral peak position. Raman spectra of $\mathrm{Zn}$ doped $\mathrm{CdS}$ thin films were recorded in the spectral region of $200-800 \mathrm{~cm}^{-1}$ as shown in Fig. 6a-e. The spectrum shows first order longitudinal optical phonon frequency (1LO) at $302 \mathrm{~cm}^{-1}$ and a weak first order longitudinal optical phonon frequency (2LO) at $603 \mathrm{~cm}^{-1}$. The $1 \mathrm{LO}$ peak shifts towards the lower frequency side and broadening with the increase of $\mathrm{Zn}$ content in $\mathrm{CdS}$ by exhibiting asymmetric nature [28]. The frequency shift in Raman peaks is due to the nanoparticles grain size effect and the decrease in the crystallite size of the films also indicates the asymmetry [29]. The 1 LO modes of the films shifted towards the lower frequency may be due to stress, strain effects, phonon confinement, defects, and variation in phonon relations with the grain size
[30]. It is clearly observed that the change in the lattice parameter is due to lowering the phonon frequencies and these results are consistent with the XRD analysis.

\subsection{UV-Visible absorption spectra}

Figure 7a shows the UV-Vis absorption spectra of Zn doped $\mathrm{CdS}$ thin films in the wavelength range from 300 to $800 \mathrm{~nm}$. When the doping concentration of $\mathrm{Zn}$ is increased in $\mathrm{CdS}$, the absorption edge was shifted towards the lower wavelength side because of proper substitution of $\mathrm{Zn}^{2+}$ into the $\mathrm{Cd}^{2+}$ ions. The absorption spectrum exhibits a sharp edge in a wavelength range of $455-472 \mathrm{~nm}$. The blue-shift absorption edge and the presence of excitonic transitions indicate quantum confinement effect [31]. The absorption edge shifted towards shorter wavelength with the increase of $\mathrm{Zn}$ concentration in $\mathrm{CdS}$, indicating an increase in the optical band gap values. The optical band gap of $\mathrm{Zn}$ doped $\mathrm{CdS}$ thin films were obtained by extrapolating straight line portion of $(a h v)^{2}$ versus hv as shown in Fig. $7 \mathrm{~b}$. The optical band gap values increased from 2.63 to $2.73 \mathrm{eV}$ with the increase of $\mathrm{Zn}$ concentration in $\mathrm{CdS}$ thin films due to the quantum confinement effect. These results are in consistency with the previous reported values for $\mathrm{Zn}$ doped CdS $[32,33]$. When the $\mathrm{Zn}$ content is increased in CdS thin films, the shifting of absorption edge towards shorter wavelength, implies the tuning of the optical band gap. The band gap tailoring will be useful in design of suitable window materials for the fabrication of solar cells. The addition of $\mathrm{Zn}$ in $\mathrm{Cd}-\mathrm{S}$ can also improve the open circuit voltage and short circuit current in hetero-junction devices as a result of decrease of absorption losses in the window layer. It is expected that the $\mathrm{Zn}$ doped $\mathrm{CdS}$ will increase the efficiency of the solar cell.

The effective mass approximation method is used to calculate the particles size with the following relation

$E_{g n}=E_{g b}+\frac{h^{2} \pi^{2}}{2 m \times R^{2}}$

where $E_{g n}$ and $E_{g b}$ are the band gap values of nanocrystalline $\mathrm{CdS}$ and bulk $\mathrm{CdS}$ semiconductor $\left(\mathrm{E}_{\mathrm{gb}}=2.4 \mathrm{eV}\right), \mathrm{m}^{*}$ is the effective mass of the electron $\left(=0.19 \mathrm{~m}_{\mathrm{o}^{\prime}} \mathrm{m}_{\mathrm{o}}\right.$ is the rest mass of electron) and $R$ is the particle radius $[34,35]$. The particle size of the prepared samples was calculated and summarized in Table 3. The particle size estimated from the absorption spectra decreased from 21 to $8 \mathrm{~nm}$ with the increase of $\mathrm{Zn}$ content in CdS thin films. 

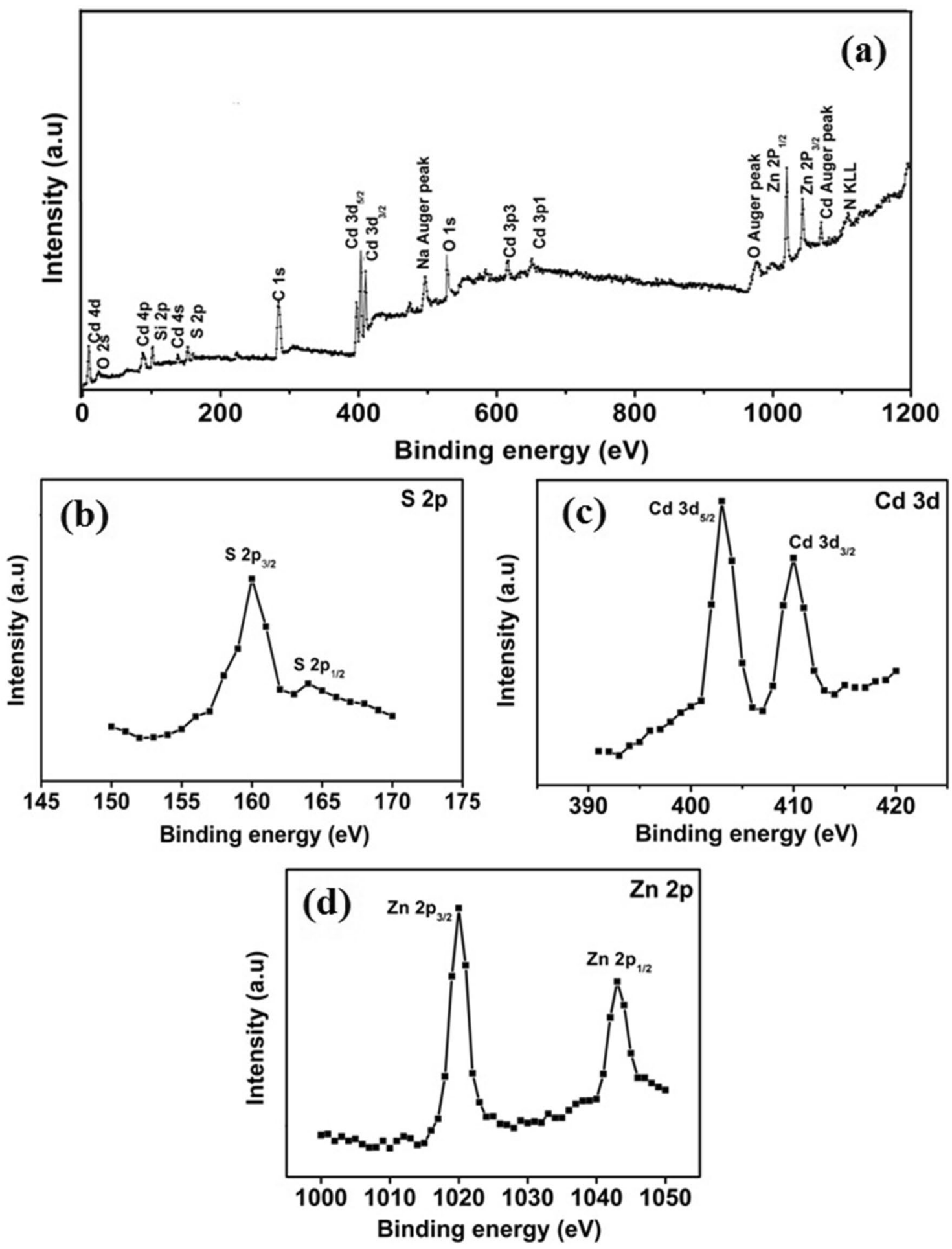

Fig. 5 XPS spectra of $6 \%$ Zn doped CdS thin film. a Full spectrum scan, b Cd 3d core level spectra, c S $2 p$ core level spectra, d Zn $2 p$ core level spectra

\subsection{Thermoelectric properties}

The Seebeck coefficient (S) is defined as the ratio of voltage difference $(\Delta \mathrm{V})$ that develops as a function of a temperature difference $(\Delta \mathrm{T})$ across the sample. It is obtained by the equation

$\mathrm{S}=\frac{\Delta V}{\Delta T}$ 

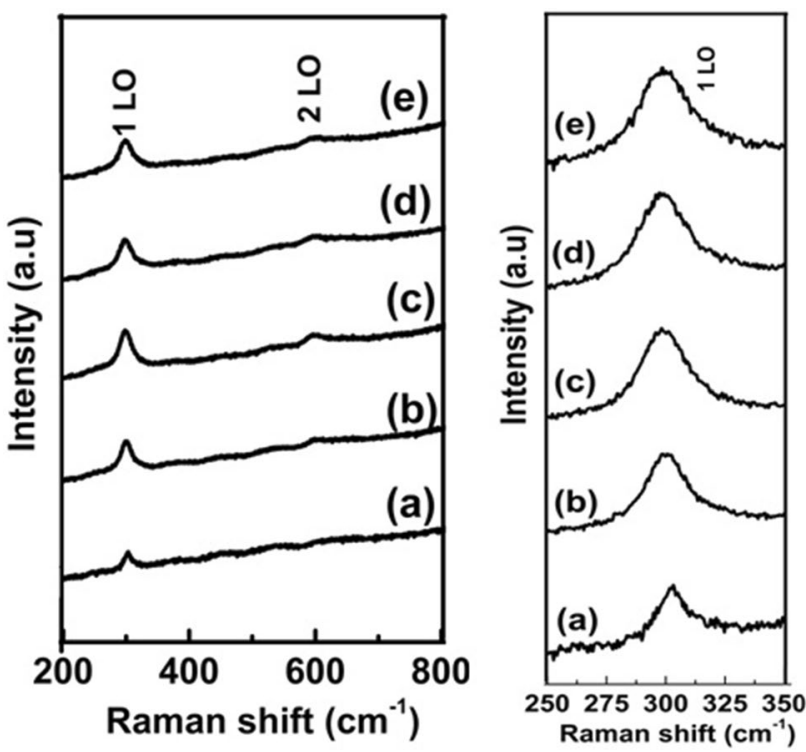

Fig. 6 Raman spectra of (a) 2\%, (b) 4\%, (c) 6\%, (d) $8 \%$ and (e) $10 \%$ Zn doped CdS thin films

For all the $\mathrm{Zn}$ doped $\mathrm{CdS}$ thin films, thermoelectric voltage is found to be negative indicating $n$-type semiconducting behaviour. It is noticed from the Fig. 8 a that the Seebeck coefficient (S) or thermoelectric power of $\mathrm{Zn}$ doped $\mathrm{CdS}$ thin films increases from $1.97 \times 10^{-5}$ to $3.28 \times 10^{-5} \mathrm{~V} \mathrm{~K}^{-1}$ with the increase of $\mathrm{Zn}$ dopant. It is also noticed that the Seebeck coefficient of the films increases with the temperature, which is consistent for a degenerate semiconductor. This observation is in well agreement with the general fact that higher conductivity exhibits low thermoelectric power [36].

The carrier concentration ( $n$ ) is estimated by using the equation

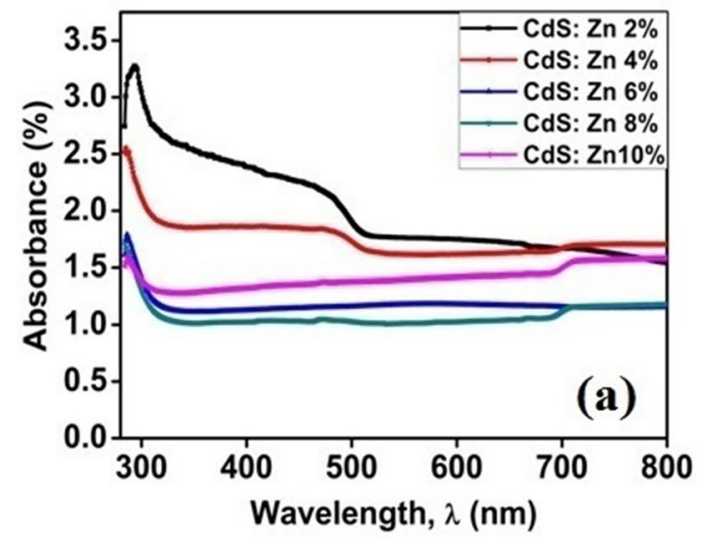

$S=\left(\frac{8 \pi^{2} k_{B}^{2}}{3 e h^{2}}\right) \cdot\left(m^{*} T\right) \cdot\left(\frac{\pi}{3 n}\right)^{2 / 3}$

where $\mathrm{k}_{\mathrm{B}}\left(=8.61 \times 10^{-5} \mathrm{eV} \mathrm{K}^{-1}\right)$ is the Boltzmann constant, $\mathrm{e}$ is the charge of electron, $\mathrm{h}\left(=4.135 \times 10^{-15} \mathrm{eV} \mathrm{Hz}^{-1}\right)$ is the Planck's constant and $\mathrm{m}^{*}$ is the effective mass of the charge carrier. From the measured values of Seebeck coefficient at different temperatures, the carrier concentration is calculated. The carrier concentration increases from $4.68 \times 10^{19}$ to $1.07 \times 10^{20} \mathrm{~cm}^{-3}$ with increase of $\mathrm{Zn}$ dopant from 2 to 10 at wt\% in CdS thin films (shown in Fig. 8b). The increase in carrier concentration of $\mathrm{Zn}$ doped $\mathrm{CdS}$ thin films will improve the electrical conductivity, but the Seebeck coefficient will be decreased. Figure $8 \mathrm{c}$ shows the temperature dependence of electrical conductivity $(\sigma)$ of $Z n$ doped $C d S$ thin films. The electrical conductivity increases with the increase of temperature for all compositions of $\mathrm{Zn}$ in $\mathrm{CdS}$ thin films due to the improvement in carrier density of the films.

Thermal conductivity $(\mathrm{k})$ of the material consists of lattice thermal conductivity $\left(k_{L}\right)$ arises from heat transporting phonons and electronic thermal conductivity $\left(k_{e}\right)$ from heat carrying charge carriers moving through the lattice. Therefore, the equation that describes total thermal

Table 3 Particle size of $\mathrm{Zn}$ doped CdS thin films calculated from absorption spectra

\begin{tabular}{llll}
\hline $\begin{array}{l}\text { Doping con- } \\
\text { centration of } Z n \\
\text { (wt\%) }\end{array}$ & $\begin{array}{l}\text { Absorption } \\
\text { edge, } \lambda(n m)\end{array}$ & $\begin{array}{l}\text { Optical band } \\
\text { gap, } E_{g}(\mathrm{eV})\end{array}$ & $\begin{array}{l}\text { Particle size from } \\
\text { band shift }(\mathrm{nm})\end{array}$ \\
\hline 2 & 472 & 2.63 & 21 \\
4 & 468 & 2.65 & 18 \\
6 & 462 & 2.68 & 14 \\
8 & 458 & 2.71 & 10 \\
10 & 455 & 2.73 & 8 \\
\hline
\end{tabular}

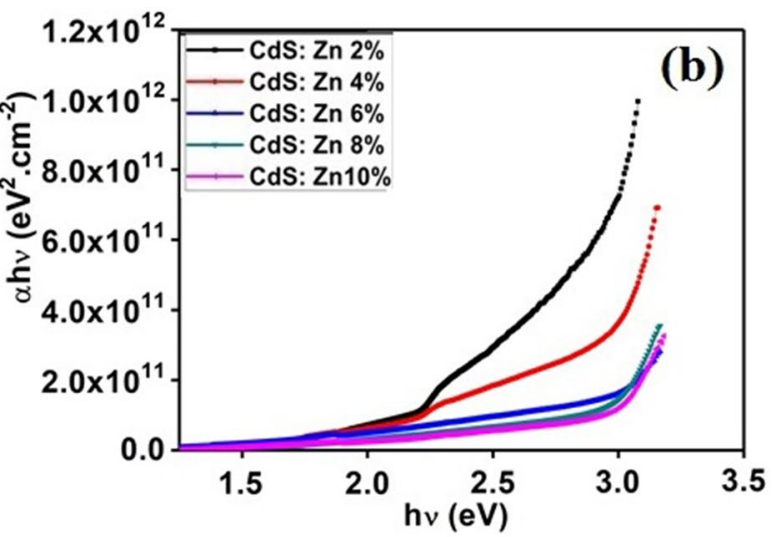

Fig. 7 a UV-Visible absorption spectra of Zn doped CdS thin films, b (ahv) ${ }^{2}$ versus hv curves for the determination of optical band gap 

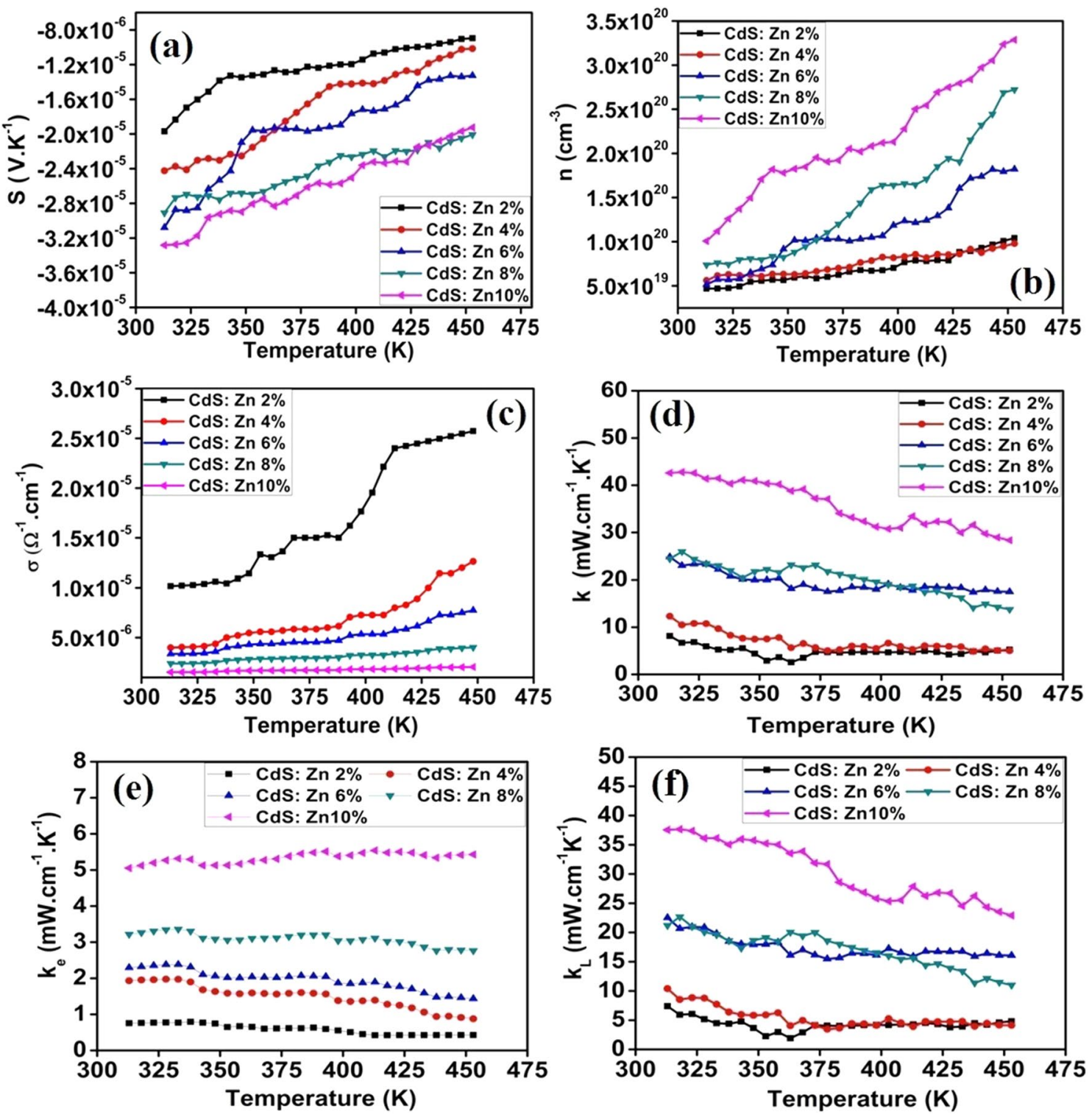

Fig. 8 Thermoelectric properties of Zn doped CdS thin films as a function of temperature: a Seebeck coefficient; $\mathbf{b}$ carrier concentration; $\mathbf{c}$ electrical conductivity; $\mathbf{d}$ total thermal conductivity; $\mathbf{e}$ electronic thermal conductivity and $\mathbf{f}$ lattice thermal conductivity

conductivity is in the form: $\mathrm{k}=\mathrm{k}_{\mathrm{e}}+\mathrm{k}_{\mathrm{L}}$. The total thermal conductivity of $\mathrm{Zn}$ doped $\mathrm{CdS}$ thin films is calculated by using the equation [37]

$\mathrm{k}=\frac{\mathrm{V} \cdot \mathrm{l} \cdot \mathrm{l}}{\Delta T \cdot \mathrm{A}}$

$V \cdot I$ is the heat power, $I$ is the probe separation between the two thermocouples, $\Delta T$ is the temperature difference between the thermocouple and $A$ is the cross-sectional area. The temperature dependent thermal conductivity of $\mathrm{Zn}$ doped $\mathrm{CdS}$ thin films measured in the range of $313-453 \mathrm{~K}$ is shown in Fig. 8d. The total thermal conductivity ( $k$ ) of $\mathrm{Zn}$ doped $\mathrm{CdS}$ thin films decreased with the increase in temperature whereas it increased with the increase of $\mathrm{Zn}$ content in CdS thin films due to the dominant of phonon scattering at higher temperatures. The lower values of thermal conductivity may be due to the presence of porosity in the films. The electronic thermal conductivity $\left(k_{e}\right)$ of $Z n$ doped $C d S$ thin films was evaluated using the Wiedemann-Franz relation [38]

$\mathrm{k}_{\mathrm{e}}=\mathrm{L} \sigma \mathrm{T}$

where $L=2.45 \times 10^{-8}{\mathrm{~W} \Omega \mathrm{K}^{-2}}, \sigma$ is the electrical conductivity, $\mathrm{T}$ is the absolute temperature (in Kelvin). The lattice thermal conductivity $\left(k_{L}\right)$ of the prepared thin films is calculated by subtracting the carrier part from the total thermal conductivity values. Figure 8 e shows the variation of 
lattice thermal conductivity $\left(k_{L}\right)$ of $Z n$ doped CdS thin films with the temperature. It exhibits a decreasing trend with increasing temperature and $k_{L}$ values increases from 7.38 to $37.54 \mathrm{~mW} \mathrm{~cm}^{-1} \mathrm{~K}^{-1}$ with the increase of $\mathrm{Zn}$ content in $\mathrm{CdS}$. This inverse temperature dependence of $\mathrm{k}_{\mathrm{L}}$ indicates that the films exhibit Umklapp phonon-phonon scattering at higher temperatures.

\section{Conclusions}

Zn doped CdS thin films were synthesized by sol-gel spin coating technique on glass substrates by varying the $Z n$ concentration from 2 to $10 \mathrm{wt} \%$. XRD studies reveal that the $\mathrm{Zn}$ doped $\mathrm{CdS}$ thin films exhibit cubic phase structure. With the increase of $\mathrm{Zn}$ content in $\mathrm{CdS}$ thin films, all the diffraction peaks shift towards the higher diffraction angles. The elemental analysis of the films is determined from XPS and EDS studies. From the Raman spectra, the first order longitudinal optical phonon frequency (1LO) shifts towards the lower frequency side and the frequency shift indicate the grain size effect. The absorption edge of thin films shifts towards the shorter wavelength region and the optical band gap of the $\mathrm{Zn}$ doped CdS thin films increased from 2.63 to $2.73 \mathrm{eV}$. The particle size calculated from the shift of optical band gap supports the formation of nanostructured thin films. The negative values of Seebeck coefficient for $\mathrm{Zn}$ doped $\mathrm{CdS}$ thin films indicate $\mathrm{n}$-type semiconducting behaviour. The carrier concentration of $\mathrm{Zn}$ doped $\mathrm{CdS}$ thin films is in the range of $10^{19}-10^{20} \mathrm{~cm}^{-3}$. It is also observed that the electrical conductivity of $\mathrm{Zn}$ doped $\mathrm{CdS}$ thin film decreases with an increase in temperature. Our results indicate that the prepared ternary $\mathrm{Zn}$ doped CdS semiconductor thin films fabricated via sol-gel spin coating method will be suitable for optoelectronic devices such as the window layer for solar cell applications.

Acknowledgements The authors are gratefully acknowledged to Centre for Nano Science and Engineering (INUP), IISc, Bangalore India for providing facilities FESEM, AFM, EDS, XPS, Optical absorption and Raman studies.

\section{Compliance with ethical standards}

Conflict of interest The authors declare that they have no conflict of interest.

\section{References}

1. Devjyoti L, Tarkeshwar S, Ayush K (2018) Influence of Cu doping on optical properties of $(\mathrm{Cd}-\mathrm{Zn}) \mathrm{S}$ nanocrystalline thin films: a review. J Mater Sci Mater Electron 29:688-713. https ://doi.org/10.1007/s10854-017-7963-6

2. Indu Y, Dhravir SA, Rachna A (2016) Cu-doped $\mathrm{Cd}_{1-x} \mathrm{Zn}_{\mathrm{x}}$ S alloy: synthesis and structural investigations. Appl Phys A 122:245 (1-6). https://doi.org/10.1007/s00339-016-9745-z

3. Werta SZ, Echendu OK, Dejene FB (2019) Physico-chemical studies of $\mathrm{Cd}_{1-\mathrm{x}} \mathrm{Zn}_{\mathrm{x}} \mathrm{S}$ thin films produced by simple twoelectrode electro deposition system for solar cell application. J Mater Sci Mater Electron 30:6201-6211. https://doi. org/10.1007/s10854-019-00922-z

4. Sathyamoorthy $R$, Sudhagar $P$, Balerna A, Balasubramanian C, Bellucci S, Popov Al, Asokan K (2010) Surfactant-assisted synthesis of $\mathrm{Cd}_{1-x} \mathrm{Co}_{x} \mathrm{~S}$ nanocluster alloys and their structural, optical and magnetic properties. J Alloys Compd 493:240-245. https://doi.org/10.1016/j.jallcom.2009.12.063

5. Mohammad H, Zandi MH, Gorji NE (2015) SCAPS modeling for degradation of ultrathin CdTe films: materials interdiffusion. JOM 67:2062-2070. https://doi.org/10.1007/s1183 7-014-1286-3

6. Jayaramaiah JR, Shamanth R, Jayanth V, Shamala KS (2016) Optical investigation on zinc doped cadmium sulphide nanocrystalline thin films. Curr Appl Phys 16:799-804. https ://doi.org/10.1016/j.cap.2016.04.011

7. Mahdi MA, Hassan JJ, Hassan Z, Ng SS (2012) Growth and characterization of $\mathrm{Zn}_{\mathrm{x}} \mathrm{Cd}_{1-\mathrm{x}} \mathrm{S}$ nanoflowers by microwave-assisted chemical bath deposition. J Alloys Compd 541:227-233. https ://doi.org/10.1016/j.jallcom.2012.05.123

8. Lee JH, Song WC, Yi JS, Yang KJ, Han WD, Hwang J (2003) Growth and properties of the $\mathrm{Cd}_{1-\mathrm{x}} \mathrm{Zn}_{\mathrm{x}} \mathrm{S}$ thin films for solar cell applications. Thin Solid Films 431-432:349-353. https:// doi.org/10.1016/S0040-6090(03)00526-1

9. Raviprakash Y, Bangera KV, Shivakumar GK (2009) Preparation and characterization of $\mathrm{Cd}_{x} \mathrm{Zn}_{1-x} \mathrm{~S}$ thin films by spray pyrolysis technique for photovoltaic applications. Sol Energy 83:16451651. https://doi.org/10.1016/j.solener.2009.06.004

10. Bakly AAK, Spencer BF, O'Brien P (2018) The deposition of thin films of cadmium zinc sulfide $\mathrm{Cd}_{1-x} \mathrm{Zn}_{\mathrm{x}} \mathrm{S}$ at $250^{\circ} \mathrm{C}$ from spincoated xanthato complexes: a potential route to window layers for photovoltaic cells. J Mater Sci 53:4360-4370. https:// doi.org/10.1007/s10853-017-1872-1

11. Tomita Y, Kawai T, Hatanaka Y (1994) Properties of sputterdeposited CdS/CdTe heterojunction photodiode. Jpn J Appl Phys 33:3383-3388. https://doi.org/10.1143/JJAP.33.3383

12. Smith PB (1992) Low temperature, low pressure CdZnS films produced by metal organic chemical vapor deposition. J Vac Sci Technol A 10:897-902. https://doi.org/10.1116/1.577691

13. Wu BJ, Cheng H, Guha S, Haase MA, De Puydt JM, Meis-Haugen G, Qiu J (1993) Molecular beam epitaxial growth of CdZnS using elemental sources. Appl Phys Lett 63:2935-2937. https ://doi.org/10.1063/1.110278

14. Bhattacharjee B, Mandal SK, Chakrabarti K, Ganguli D, Chaudhuri S (2002) Optical properties of $\mathrm{Cd}_{1-\mathrm{x}} \mathrm{Zn}_{\mathrm{x}} \mathrm{S}$ nanocrystallites in sol-gel silica matrix. J Phys D Appl Phys 35:2636-2642. https://doi.org/10.1088/0022-3727/35/20/324

15. Pathan HM, Lokhande CD (2004) Deposition of metal chalcogenide thin films by successive ionic layer adsorption and reaction (SILAR) method. Bull Mater Sci 27:85-111. https://doi. org/10.1007/BF02708491

16. Patil NB, Nimbalkar AR, Patil MG (2018) ZnO thin film prepared by a sol-gel spin coating technique for $\mathrm{NO}_{2}$ detection. Mater Sci Eng B 227:53-60. https://doi.org/10.1016/j.mseb.2017.10.011

17. Jana S, Maity R, Das S, Mitra MK, Chattopadhyay KK (2007) Synthesis, structural and optical characterization of nanocrystalline ternary $\mathrm{Cd}_{1-\mathrm{x}} \mathrm{Zn}_{\mathrm{x}} \mathrm{S}$ thin films by chemical process. Phys $\mathrm{E}$ 39:109-114. https://doi.org/10.1016/j.physe.2007.01.009 
18. Yang F, Yan NN, Huang S, Sun Q, Zhang LZ, Yu Y (2012) Zn doped CdS nano architectures prepared by hydrothermal synthesis: Mechanism for enhanced photocatalytic activity and stability under visible light. J Phys Chem C 116:9078-9084. https://doi. org/10.1021/jp300939q

19. Alehdaghi $H$, Marandi $M$, Molaei $M$, Irajizad A, Taghavinia $N$ (2014) Facile synthesis of gradient alloyed $\mathrm{Zn}_{\mathrm{x}} \mathrm{Cd}_{1-\mathrm{x}} \mathrm{S}$ nanocrystals using a microwave-assisted method. J Alloys Compd 586:380-384. https://doi.org/10.1016/j.jallcom.2013.09.190

20. Bedir M, Kayali R, Oztas M (2002) Effect of the Zn concentration on the characteristic parameters of $\mathrm{Zn}_{\mathrm{x}} \mathrm{Cd}_{1-\mathrm{x}} \mathrm{S}$ thin films developed by spraying pyrolysis method under the nitrogen atmosphere. Turk J Phys 26:121-126

21. Sekhar H, Rao DN (2012) Spectroscopic studies on Zn-doped CdS nanopowders prepared by simple coprecipitation method. J Mater Sci 47:1964-1971. https://doi.org/10.1007/s1085 3-011-5991-9

22. Hossain MS, Islam MA, Huda Q, Aliyu MM, Razykov T, Alam MM, AlOthman ZA, Sopian K, Amin N (2013) Growth optimization of $\mathrm{Zn}_{\mathrm{x}} \mathrm{Cd}_{1-x} \mathrm{~S}$ thin films by radio frequency magnetron co-sputtering for solar cell applications. Thin Solid Films 548:202-209. https://doi.org/10.1016/j.tsf.2013.09.061

23. Devadoss I, Muthukumaran S (2016) Band gap tailoring and yellow band emission of $\mathrm{Cd}_{0.9-\mathrm{x}} \mathrm{Mn}_{\mathrm{x}} \mathrm{Zn}_{0.1} \mathrm{~S}$ ( $\mathrm{x}=0$ to 0.05 ) nanoparticles: influence of Mn concentration. Mater Sci Semicond Process 41:282-290. https://doi.org/10.1016/j.mssp.2015.09.020

24. Ma L, Ai X, Wu X (2016) Effect of substrate and Zn doping on the structural, optical and electrical properties of $\mathrm{CdS}$ thin films prepared by CBD method. J Alloys Compd 691:399-406. https:// doi.org/10.1016/j.jallcom.2016.08.298

25. Selvan G, Abubacker MP, Balu AR (2016) Structural, optical and electrical properties of $\mathrm{Cl}$-doped ternary $\mathrm{CdZnS}$ thin films towards optoelectronic applications. Optik 127:4943-4947. https://doi.org/10.1016/j.ijleo.2016.02.047

26. Pal U, Samanta D, Ghorai S, Samantaray BK, Chaudhuri AK (1992) Structural characterization of cadmium selenide thin films by X-ray diffraction and electron microscopy. J Phys D Appl Phys 25:1488-1494. https://doi.org/10.1088/0022-3727/25/10/014

27. Chalana SR, Ganesan V, Pillai VPM (2015) Surface plasmon resonance in nanostructured Ag incorporated ZnS films. AIP Adv 5:107207. https://doi.org/10.1063/1.4933075

28. Chuu DS, Dai CM, Hsieh CF, Tsai CT (1991) Raman investigations of the surface modes of the crystallites in CdS thin films grown by pulsed laser and thermal evaporation. J Appl Phys 69:84028404. https://doi.org/10.1063/1.347405

29. Vineeshkumar TV, Rithesh Raj D, Prasanth $S$, Unnikrishnan NV, Philip R (2014) Structural and optical studies of $\mathrm{Zn}_{1-x} \mathrm{Cd}_{x} \mathrm{~S}$ quantum dots synthesized by in situ technique in PVA matrix. Opt Mater 37:439-445. https://doi.org/10.1016/j.optma t.2014.06.037

30. Zhao PQ, Liu LZ, Xue HT, Wu XL, Shen JC, Chu PK (2013) Resonant Raman scattering from CdS nanocrystals enhanced by interstitial Mn. Appl Phys Lett 102:061910. https://doi. org/10.1063/1.4792512

31. Unni C, Philip D, Smitha SL, Nissamudeen KM, Gopchandran KG (2009) Aqueous synthesis and characterization of CdS, CdS: $\mathrm{Zn}^{2+}$ and $\mathrm{CdS}: \mathrm{Cu}^{2+}$ quantum dots. Spectrochim Acta Part A 72:827832. https://doi.org/10.1016/j.saa.2008.11.027

32. Peter AJ, Lee CW (2012) Electronic and optical properties of CdS/ CdZnS nanocrystals. Chin Phys B 21:087302 (1-8). https://doi. org/10.1088/1674-1056/21/8/087302

33. Rajathi S, Subramanian NS, Ramanathan K, Senthamizhselvi M (2013) Influence of deposition temperature on the structural and optoelectronic properties of CdZnS thin films. Adv Mater Res 699(2013):606-611. https://doi.org/10.4028/www.scientific .net/AMR.699.606

34. Devjyoti L, Pillai S, Ayush K (2018) Effect of Tb doping on structural and optical Properties of $\left(\mathrm{Cd}_{0.8}-\mathrm{Zn}_{0.2}\right) \mathrm{S}$ films deposited through a chemical route. J Electron Mater 47:6532-6539. https ://doi.org/10.1007/s11664-018-6554-5

35. Muruganandam S, Anbalagan G, Murugadoss G (2014) Synthesis and structural, optical and thermal properties of $\mathrm{CdS}: \mathrm{Zn}^{2+}$ nanoparticles. Appl Nanosci 4:1013-1019. https://doi.org/10.1007/ s13204-013-0284-Z

36. Urmila KS, Asokan TN, Philip RR, Ganesan V, Okram GS, Pradeep B (2014) Structural, optical, electrical and low temperature thermoelectric properties of degenerate polycrystalline $\mathrm{Cu}_{7} \mathrm{Se}_{4}$ thin films. Phys Status Solidi B 251:689-696. https://doi.org/10.1002/ pssb.201349183

37. Rowe DM (2008) Thermoelectric handbook, macro to nano. CRC Press, Boca Raton

38. Raju Ch, Falmbigl M, Rogl P, Heinrich P, Royanian E, Bauer E, Mallik RC (2014) Thermoelectric properties of $\mathrm{Zn}$ doped $\mathrm{Cu}_{2} \mathrm{SnSe}_{3}$. Mater Chem Phys 147:1022-1028. https://doi.org/10.1016/j. matchemphys.2014.06.054

Publisher's Note Springer Nature remains neutral with regard to jurisdictional claims in published maps and institutional affiliations. 